\title{
Notas Sobre o Conceito de Guerra Revolucionária e sua Expressão Legal
}

\author{
Enrique Ricardo Lewandowski \\ Professor Assistente Doutor da Faculdade \\ de Direito da Universidade de São Paulo
}

\section{O ADVENTO DA GUERRA FRIA}

A origem remota do conceito de guerra revolucionária pode ser encontrada na resposta dos EUA à chamada guerra fria. O termo guerra fria, empregado pela primeira vez pelo conselheiro presidencial Bernard Baruch, durante um debate no Congresso norte-americano, em 1947, identifica o estado de beligerância virtual que se instaurou, a partir do término da Segunda Grande Guerra, entre as potências ocidentais, capitaneadas pelos EUA, e o bloco comunista, liderado pela URSS.

Essa guerra que se opõe, em princípio, à guerra quente, ou seja, a um confronto armado direto, trava-se em vários campos - político, econômico psicológico e militar —, lançando mão preferencialmente de manobras diplomáticas, ameaças, pressões, espionagem, propaganda, etc, $\mathrm{O}$ recurso às armas, quando ocorre, realiza-se de forma limitada e, via de regra, indireta, visto que, com o advento e disseminação das armas atômicas, as vantagens iniciais de uma ação bélica direta e generalizada seriam anuladas pelos insuportáveis prejuízos que, inevitavelmente, todas as partes envolvidas no conflito sofreriam, em razão da destruição reciprocamente infligida.

A Guerra do Vietnã, cujas raízes alcançam o fim da Segunda Guerra Mundial, a Guerra da Coréia, iniciada em 1950, a Invasão da Hungria, ocorrida em 1956, a Revolução Cubana, vitoriosa em 1959, e inúmeros outros conflitos semelhantes, travados nos mais diversos pontos do globo, constituiriam, segundo os analistas, exemplos daquilo que se convencionou chamar de guerra fria. Nesse contexto, a partir da doutrina Truman - segundo a qual os EUA dariam apoio aos «povos livres que estão resistindo a uma tentativa de subjugação por minorias armadas ou por pressões externas» (1) - e com base

(1) A Dictionary of Politics, editado por Walter Laqueur, New York, The Free Press, 1973, pág. 486 . 
na interpretação dos escritos de Mao-Tsé Tung, Ho Chi-Minh, Nguyen Giap, Che Guevara e outros, os norte-americanos elaboraram uma doutrina militar que tinha por objetivo combater a guerra não convencional ou revolucionária, considerada a principal ameaça estratégica do comunismo internacional e que seria desencadeada, prioritariamente, nos países do Terceiro Mundo $\left({ }^{2}\right)$. Essa doutrina de combate à guerra revolucionária foi transmitida aos militares latino-americanos, especialmente a partir da década de 60 , pelos colégios militares dos EUA localizados na região do Canal do Panamá, entre outros centros de treinamento $\left({ }^{3}\right)$.

\section{A ESCOLA SUPERIOR DE GUERRA E A GUERRA REVOLUCIONÅRIA}

No Brasil esse conjunto de idéias passou a integrar as teses centrais da Doutrina de Segurança Nacional, desenvolvida pela Escola Superior de Guerra (ESG). A Escola Militar brasileira, criada pela Lei $\mathrm{n}^{9} \mathbf{7 8 5}$, de 20 de agosto de 1949, teve como modelos a Escola Nacional de Guerra e a Escola Industrial das Forças Armadas dos EUA e também, a experiência inglesa e francesa no setor $\left.{ }^{4}\right)$. Foi organizada por uma comissão constituída por militares, em sua maioria oriundos da campanha da Força Expedicionária Brasileira (FEB) na Itália, que, sob a coordenação do General Cordeiro de Farias, contou com a colaboração de uma missão especial norte-americana ${ }^{5}$ ). Segundo a lei que a instituiu, a ESG seria «um instituto de altos estudos destinados a desenvolver conhecimentos necessários ao exercício de funções de direção e planejamento da segurança nacional», admitindo civis e militares em seus cursos.

A Escola, pelas suas próprias origens, sempre foi muito ligada às doutrinas militares norte-americanas e, como tal, desde a sua fundação absorveu a preocupação com a guerra fria e com o combate à guerra revolucionária. Alfred Stepan, conhecido brazilianist, mostra que «desde o princípio, a ESG era anticomunista e estava empenhada na guerra fria. Mesmo antes que a ênfase na guerra fria mudasse, nos Estados Unidos, da guerra atômica para a guerra revolucionária, a ESG tornou-se o centro do pensamento ideológico relativo à estratégia contrarevolucionária no Brasil» ( ${ }^{6}$ ). De fato, já em 1959, o General Golbery do Couto e Silva, um dos fundadores e principais pensadores da ESG, afirmava «que a maior probabilidade atualmente é de guerra limitada, de conflito localizado e acima de tudo a agressão comunista indireta,

(2) Cf. Joseph Comblin, A Ideologia da Segaranca Nacional, Rio de Janeiro, Civilização Brasileira, 1975, pág. 44.

(3) Idem, op. cit., loc. cit.

(4) Cf. José Alfredo Amaral Gurgel, Seguranca e Desenvolvimento, Rio de Janeiro, José Olympio, 1975, pág. 27 e segs., e Eliézer R. de Olivefra, As Forças Armadas: Política - Ideologia no Brasil, Petrópolis, 2a ed., Vozes, 1976, pág. 21 e segs.

(5) Eliézer de Oliveira, op. cit., pág. 21.

(6) Alfred Stepan, Os Militares na Política, Rio de Janeiro, Artenova, 1975, pág. 132. 
que capitaliza descontentamentos locais, frustrações da miséria e da fome e as justas ansiedades nacionalistas. . .» (7).

Assim, quando a doutrina norte-americana da guerra revolucionária ganhou corpo e foi disseminada nas escolas militares dos países aliados, especialmente latino-americanos, as novas idéias encontraram terreno fértil onde germinar.

Com efeito, a Escola Superior de Guerra encontrava-se ideologicamente preparada para receber essa nova doutrina estratégica, trabalhado sobre suas hipóteses. Nesse sentido, o Manual Básico MB-75 da ESG, estudo que corporifica as principais teses da Doutrina de Segurança Nacional, assinala que «o equilíbrio existente entre os blocos ideológicos - quer no campo, nuclear, quer no campo aeroespacial torna muito remota a possibilidade de um confronto direto entre os antagonistas. E a razão, por simples, é aceita sem discussão: o perigo de um suicídio coletivo da humanidade. Em consequiência passa a prevalecer a estratégia da ação indireta que, para o Bloco Oriental, encontra na chamada guerra revolucionária a sua grande expressão» $\left(^{8}\right)$.

A crescente preocupação com a guerra revolucionária pode ser demonstrada a partir do exame do currículo da ESG. Em 1956, por exemplo, a programação da Escola não fazia menção a conferências sobre guerra de contraguerrilha, segurança interna ou comunismo, sendo que, de 1961 em diante, a preocupação com esses tópicos aumentou a tal ponto que, em 1968, o currículo passou a destinar 222 horas de aula sobre segurança interna, 129 horas à guerra irregular e somente 21 horas aos temas clássicos de defessa territorial ( ${ }^{9}$ ).

Mas, qual é o conceito da ESG de guerra revolucionária? Trata-se, para a Escola, do «conflito, normalmente interno, de concepção marxista-leninista, inspirado e, até mesmo, auxiliado do exterior, que, utilizando intensivamente a ação psicológica e todas as formas de subversão e violência, visa à conquista do poder pelo controle progressivo da nação» (10). Para a ESG, a guerra revolucionária é sempre subversiva, universal, permanente e total (11).

Para combater a guerra revolucionária, a ESG, assegurando que «a luta contra-revolucionária é de toda a nação», propõe na obra citada, as seguintes medidas:

— «estimular o desenvolvimento para combater as injustiças e as desigualdades entre os homens;

- «realizar eficiente ação psicológica associada ao correto emprego da comunição social, objetivando a afirmação democrática e o fortalecimento moral da sociedade;

(7) Citado por Alfred Stepan, op. cit., pág. 132.

(8) Manual Básico da Escola Superior de Guerra MB-75, 1975, pág. 297.

(9) Cf. Alfred Stepan, op. cit., pág. 133.

(10) Manual Básico. ., păg. 304.

(11) Ibidem, pág. 311. 
- «aprimorar, continuamente, a eficiência administrativa;

- «elaborar e aplicar a legislação adequada à prevenção e combate à subversão (grifos nossos);

- «realizar o planejamento global com vistas à guerra revolucionária e, dentro dele, o Plano de Segurança Interna;

tínua» $\left({ }^{12}\right)$.

- «pôr em execução esses planos, de forma agressiva e con-

Desse posicionamento decorre o conceito de segurança nacional da ESG, que consiste no «grau de garantia que através de ações políticas, econômicas, psicossociais e militares - o Estado proporciona, em determinada época, à nação que jurisdiciona, para a conquista ou manutenção dos objetivos nacionais, a despeito dos antagonismos ou pressões existentes ou potenciais» (13). Para a Escola, os objetivos nacionais constituem-se na «cristalização de interesses e aspirações que, em determinada fase da evolução da comunidade, toda uma nação procura satisfazer» $\left({ }^{14}\right)$.

\section{GUERRA REVOLUCIONARIA E DOUTRINA DA SEGURANCA NACIONAL}

O Marechal Castello Branco, primeiro presidente da Revolução de 1964, elaborou uma interessante síntese das idéias estratégicas então dominantes na Escola, ao proferir a aula inaugural do ano letivo de 1967 da ESG, demonstrando a «dilatação do conceito de segurança nacional, bastante diferenciado, hoje, do conceito de defesa nacional». Para o expositor, «o conceito tradicional de defesa nacional coloca mais ênfase sobre os aspectos militares da segurança e, correlatamente, os problemas de agressão externa. Compreende, por assim dizer, a defesa global das instituições, incorporando por isso aspectos psicossociais, a preservação do desenvolvimento e da estabilidade política interna; além disso, o conceito de segurança, muito mais explicitamente que o de defesa, toma em linha de conta a agressão interna, corporificada na infiltração e subversão ideológica, até mesmo movimentos de guerrilha, formas hoje mais prováveis de conflito do que a agressão externa» ${ }^{15}$ ).

As idéias da Escola, porém, nem sempre tiveram grande repercussão extra muros, especialmente antes do Movimento de 31 de março de 1964. De acordo com o General Meira Matos, um dos principais estudiosos da geopolítica no Brasil, «de 1949 a 1964, durante 14 anos, a ESG não teve influência maior nas decisões do governo. En-

(12) Xbidem, pág. 312.

(13) Ibidem, pág. 234

(14) Tbidem, pág. 35.

(15) Citado por Carlos Meira Mattos, Brasil: Geopolitica e Destino, Rio de Janeiro, Josê Olympio 1975, págs. 61 e 62. 
tretanto, formulou sua doutrina de segurança nacional e pesquisou profundamente no campo de desenvolvimento. Formou elites civis e militares aptas a pensarem no Brasil com objetividade, como um todo, a se exercitarem na formulação de uma política de aplicação do poder nacional para a segurança, a se aprofundarem nas tentativas de selecionar os rumos para o nosso desenvolvimento. Quando veio a Revolução de 1964 a doutrina da Escola Superior de Guerra já estava formulada e exercitada em termos laboratoriais e escolares. Foi fácil para o chefe da Revolução, o Presidente Castello Branco e seus principais assessores Golbery, Ernesto Geisel, Juarez Távora, Cordeiro de Farias, todos exmilitares participantes ativos na formulação dessa doutrina, pois haviam pertencido aos quadros da ESG, tranferirem para a prática governamental a doutrina formulada durante 14 anos do casarão do Forte São João» $\left.{ }^{16}\right)$.

Com efeito, com a vitória da Revolução de 1964, as teses da ESG passaram a integrar a prática governamental, para o que contou com o apoio das «elites civis e militares» a que se refere o General Meira Matos. Em torno de 1966, segundo dados de Stepan, «a ESG tinha diplomados de muitos setores importantes da estrutura de poder política e econômica: 599 eram militares, 224, empresários particulares, havia 200 funcionários públicos dos principais ministérios e 97 órgãos autônomos do governo, 39 eram congressistas, 23 juízes federais e estaduais e 107 eram profissionais variados - como professores, economistas, escritores, médicos e sacerdotes católicos» (17). Além disso, a Associação dos Diplomados da Escola Superior de Guerra (ADESG) ativa agremiação de ex-alunos - encarregava-se, como ainda o faz, de divulgar, através de cursos pelas principais cidades do país, para as elites locais, as idéias mais importantes da doutrina da Escola.

\section{LEI DE SEGURANÇA NACIONAL}

No que respeita aos instrumentos legais de defesa do Estado, a Revolução de 1964 encontrou como principal diploma jurídico a Lei $n^{\circ}$ 1.802 , de 05 de janeiro de 1953 , elaborada pelo Congresso, sob a égide da Constituição liberal de 1964. Essa lei, tendo em vista a sua relativa brandura e limitada abrangência, não se coadunava com a idéias esquianas sobre a segurança nacional.

Baixou-se, então, um grande número de normas legais, constitucionais, para constitucionais e ordinárias, visando combater a subversão interna, dentre as quais se destaca, pela sua especificidade e rigor, a chamada Lei de Segurança Nacional.

O primeiro desses diplomas legais consistiu no Decreto-lei $n^{\circ}: 314$, de 18 de março de 1987, que objetivava, segundo sua emenda, definir os crimes contra a segurança nacional e a ordem política e social,

(16) Idem, pág. 61.

(17) Alfred Stepan, op. cit., pág. 130. 
atribuindo ao foro militar o seu julgamento. O que é curioso notar na Lei de Segurança Nacional é que esta, de forma inusitada, estabelecia em seu artigo 4\%, que «o juiz, ou Tribunal, deverá inspirar-se nos conceitos básicos da segurança nacional definidos nos artigos anteriores», ao aplicá-la.

Dessa forma, os artigos iniciais do decreto-lei fixaram as definições que deveriam nortear o intérprete. A segurança nacional, leitmotiv da ESG, era conceituada como «garantia da consecução dos objetivos nacionais contra antagonismos tanto internos como externos», compreendendo «medidas destinadas à preservação da segurança interna e externa, inclusive prevenção e repressão da guerra psicológica adversa e da guerra revolucionária ou subversiva» (art. $2^{\circ}$ e $3^{\circ}$, caput).

Logo a seguir definia-se a segurança interna que, conforme assinalava o legislador, «diz respeito à ameaças ou pressões antagônicas, de qualquer origem, forma ou natureza, que se manifestem ou produzam efeito no âmbito interno do país» (art. $3^{\circ}, \S 1^{\circ}$ ). Sintomaticamente, porém, o texto deixava de estabelecer a definição da segurança externa...

Interessantes, pela sua proximidade com o posicionamento da ESG sobre o tema, são as conceituações de guerra psicológica adversa e a de guerra revolucionária da Lei de Segurança Nacional. A primeira consiste no «emprego da propaganda e de ações no campo político, econômico, psicossocial e militar, com a finalidade de influenciar ou provocar opiniões, emoções, atitudes e comportamentos de grupos estrangeiros, inimigos, neutros e amigos, contra a consecução dos objetivos nacionais» (artigo $3^{\circ}, \S 2^{\circ}$ ). A segunda constitui-se no «conflito interno, geralmente inspirado em uma ideologia, ou auxiliado do exterior, que visa à conquista do poder pelo controle progressivo da nação», art. $3^{\circ}, \S 3^{\circ}$ ).

O Decreto-lei $n^{\circ} 314 / 67$ foi modificado em parte pelo Decreto-lei $\mathrm{n}^{\circ}$ 510, de 20 de março de 1967, que reduziu certas penas e agravou outras. Em 29 de setembro de 1969, editou-se o famoso Decreto-lei $n^{\circ}$ 898, que revogou os decretos anteriores, consolidando seus dispositivos e acrescentando novos artigos, entre os quais figuravam os que estabeleciam a pena de morte e a prisão perpétua, instituídas pelo Ato Institucional $n^{\circ}$ 14, de 05 de setembro de 1969. As conceituações preliminares, porém, que constavam da primeira Lei de Segurança Nacional, foram mantidas integralmente.

Com a revogação dos instrumentos jurídicos de exceção, por força da Emenda Constitucional $n^{\circ}$ 11, de 13 de outubro de 1978, o Decreto- lei $n^{\circ} 898 / 69$ foi substituído pela Lei $n^{\circ} 6.620$, de 17 de dezembro de 1978, que, apesar de ter sido votada pelo Congresso Nacional, manteve basicamente o espírito e a letra dos primeiros ordenamentos. A nova lei apenas introduziu um abrandamento nas sanções de modo geral, abolindo também as penas de morte e de prisão perpétua, revogadas a nível constitucional. Porém, os artigos relativos às definições foram 
mantidos, embora com pequenas modificações, consistindo a principal delas no acréscimo do rol de objetivos garantidos pela segurança nacional.

Dessa forma, pois, o conceito de guerra revolucionária ou subversiva, nascido da concepção norte-americana de guerra fria, elaborado e desenvolvido pela ESG, serviu de inspiração aos líderes do Movimento de 1964 para a composição de um diploma jurídico especial, de extrema severidade, que transcreve no próprio texto legal as definições centrais da Doutrina de Segurança Nacional, de modo a garantir a fidelidade de sua execução.

\section{CONCLUSÃO}

À guisa de conclusão, vale observar que não se conhece ainda em que medida a Lei de Segurança Nacional e as demais normas jurídicas excepcionais vigentes durante o período que sobreveio à Revolução de 1964 foram eficazes no combate a movimentos insurrecionais. Tampouco se sabe, em parte devido à rigorosa censura exercida sobre os meios de comunicação e também em virtude da proximidade dos fatos ocorridos no passado recente, insuficientemente investigados, em que extensão os temores da ESG relativos à irrupção da guerra revolucionária no Brasil concretizaram-se na realidade. Entretanto, pouco a pouco, os acontecimentos da história recente do país vão sendo revelados. Já se sabe, com efeito, que a par de uma verdadeira guerrilha urbana, cujo ponto culminante foi o seqüestro do embaixador norteamericano Charles Burke Elbrick, em setembro de 1969, a guerrilha rural eclodiu efetivamente em alguns pontos do território nacional. Em fins de 1969, um pequeno grupo de militantes da Vanguarda Popular Revolucionária, chefiado pelo ex-capitão do Exército Carlos Lamarca, no Vale do Ribeira, em São Paulo, mobilizou cerca de 5.000 homens das Forças Armadas e das Polícias Civil e Militar numa campanha que durou até meados de 1970, quando os remanescentes do grupo de revoltosos conseguiu romper o cerco das forças governamentais (18). Também na região do Araguaia, no norte brasileiro, o governo lançou, de abril de 1972 a janeiro de 1975 , aproximadamente 10.000 militares e policiais contra um foco de mais ou menos 60 guerrilheiros integrantes do Partido Comunista do Brasil, tendo a repressão cessado após o aniquilamento total das forças rebeldes (19). Os sobreviventes desses movimentos armados, com exceção de alguns poucos que conseguiram fugir para o exterior, foram presos e julgados por tribunais militares com base nos dispositivos da Lei de Segurança Nacional.

Deve-se observar, por fim, que, com o processo conhecido como abertura política, iniciado pelo quarto presidente da Revolução de 1964,

(18) Cr: Fernando Portela, Guerra de Guerrilhas no Brasil, Såo Paulo, Global, 1979, pág. 27.

(19) Ver reportagem especial no jornal Folha de São Paulo, edição de 27-08-1979, págs. 4 e 5 . 
General Ernesto Geisel, e continuado por seu sucessor, General João Figueiredo, grande parte da legislação baixada pelo regime militar foi revista. A própria Lei de Segurança Nacional sofreu substancial modificação. Com efeito, o diploma que a substituiu, Lei $\mathrm{n}^{\circ} \mathbf{7 . 1 7 0}$, de 14 de dezembro de 1983, foi completamente expurgado dos conceitos relativos à guerra revolucionária, constando em seu artigo $1^{\circ}$ que a referida lei prevê os crimes que expõem a perigo de lesão:

$\ll I$ - a integridade territorial e a soberania nacional

II - o regime representativo e democrático, a Federação e o Estado de Direito;

III - a pessoa dos chefes dos Poderes da União.»

Apesar da mudança de enfoque, e em que pese o fato de haver a nova lei definido de forma mais objetiva, em capítulo específico, os crimes contra a segurança nacional, cumpre notar que os infratores das normas desse diploma continuam submetidos ao foro castrense, que os julgará segundo os trâmites previstos no Código de Processo Penal Militar em vigor.

\section{Bibliografia Básica}

AMARaL GURGeL, José Alfredo - Seguranca e Desenvolvimento: Uma Reflexão Politica. Rio de Janeiro, Jose Olympio, 1975.

COMBLIN, Joseph - A Ideologia da Segurança Nacional: o Poder Militar na América

Latina. Rlo de Janeiro, Civilização Brasileira, 1978.

MEIRA Matos, Carlos - Brasil: Geopolitica e Destino. Rio de Janeiro, Jose Olympio, 1975.

SILVEIRA, Eliézer R. de - As Forcas Armadas: Politica e Ideologia no Brasil (19641969). Pefrópolis, 2a ed., Vozes, 1976.

SILVA MiChelena, José Augustín - Crise no Sistema Mundial: Política o Blocos de

Poder. Rio de Janeiro, Paz e Terra, 1977.

PESSOA, Mário - o Direito da Segurança Nacional. São Paulo, Revista dos Tribunais, 1971. Portela, Fernando - Guerra de Guerrilhas no Brasil. São Paulo, Global, 1979.

STEPAN, Alfred - Os Militares na Política: As Mudanças de Padrões na Vida Brasileira. Rio de Janeiro, Artenova, 1975.

Manual Básico da Escola Superior de Guerra MB-75, 1975..

A Dictionary of Politics, editado por Walter Laqueur, New York, The Free Press, 1973.

Jornal Folha de São Paulo, edição de 27-08-1979. 